\title{
Effect of Ground Flaxseed Intake on Lipidic Profile in Subjects with Dyslipidemic with and without Pharmacotherapy
}

\section{Paz Beyer ${ }^{1 *}$, Camila Escala ${ }^{1}$, Javiera Gómez ${ }^{1}$, Javiera González ${ }^{1}$ and Ximena Palma ${ }^{2}$}

${ }^{1}$ Student of Nutrition and Dietitics, Universidad de Valparaíso, Chile

${ }^{2}$ Faculty of Nutrition and Dietitics, Universidad de Valparaíso, Chile

*Corresponding Author: M Paz Beyer, Student of Nutrition and Dietitics, Universidad de Valparaíso, Chile.
Received: April 23, 2021

Published: June 07, 2021

(C) All rights are reserved by M Paz Beyer., et al.

\section{Abstract}

Background: Dyslipidemia corresponds to a number of alterations of blood lipids concentrations that is associated with health risks. Diets high in fat, family background, among others are risk factors. One way to correct lipid alterations would be to consume dietary fiber like the one present in ground flaxseed, which could contribute to the improvement of cholesterol and triglycerides levels.

General Objective: To determine the effect of daily consumption of ground flaxseed on the lipid profile of 10 dyslipidemic subjects diagnosed with a follow up of 1 month.

Methods: Participants in this study were adults, age 40-70 years old. Subjects consumed $15 \mathrm{~g}$ of ground flax in $200 \mathrm{ml}$ of water with their lunch. Blood lipid profile tests were performed before and after consumption for one month. Data was analyzed using an individual delta for each lipid profile and was compared using analysis of variance (ANOVA). To evaluate the difference in food intake the averages of each variable were compared using T-Student test.

Results: There was a statistically significant decrease in LDL cholesterol in all the participants from $184 \pm 28,38 \mathrm{mg} / \mathrm{dL}$ to $139 \pm$ $29,02 \mathrm{mg} / \mathrm{dL}$ during the 1-month follow up. The changes in levels of total cholesterol, LDL and blood triglycerides were statistically significant.

Conclusion: The daily intake of flaxseed with a meal is associated with improved levels of LDL.

Keywords: Dyslipidemia; Soluble Fiber; Lipid Profile; Ground Flax; Cholesterol

\section{Abbreviations}

TG: Triglyceride; CVC: Cardiovascular Disease; LDL cholesterol: Low-density Lipoprotein; HDL-cholesterol: High-density Lipoprotein.

\section{Introduction}

Dyslipidemia is a set of alterations in the blood concentration of lipids and components of circulating lipoproteins, at a level that means a health risk [1]. It is characterized by hypercholesterolemia, which means an increase in cholesterol levels, or hypertriglyceridemia which constitutes an increase in triglyceride (TG) concentrations. This could be due to bad lifestyle habits such as high-fat diets, sedentary lifestyles, smoking, among others. Indeed, it is predisposed to the risk of atherosclerosis, because there is a growth in the deposit of lipids in the arterial walls with the consequent formation of atherome plates [2]. Currently the prevalence of

Citation: M Paz Beyer., et al. "Effect of Ground Flaxseed Intake on Lipidic Profile in Subjects with Dyslipidemic with and without Pharmacotherapy". Acta Scientific Nutritional Health 5.7 (2021): 15-21. 
dyslipidemia in Chile according to Health Minister is $35.4 \%$ among men and women [3].

Cholesterol is a molecule that performs structural and metabolic functions for humans, it is present in the membranes of each cell where it modulates fluidity, permeability and function. It comes from the diet or is synthesized by the body, is a precursor of steroid hormones and bile acids. However, excessive tissue buildup coupled with high blood concentrations, could bring pathological consequences, this is particularly seen when the deposit is in the endothelial cells that form the arterial wall, leading to cardiovascular disease (CVD). This cholesterol can be decreased by inhibiting its main enzyme HMG Coa Reductase by drugs such as statins, but also through a diet low in saturated fats and with adequate fiber intake [6].

There are different risk factors for this disease such as: being a man over the age of 45 , a postmenopausal woman without estrogenic replacement therapy, a history of clinical atherosclerosis in first-degree relatives, smoking, hypertension, diabetes mellitus and finally HDL cholesterol less than $35 \mathrm{mg} / \mathrm{dL}$ [1].

There are different types of dyslipidemias according to clinical phenotype and etiopathogenesis [5].

Classification according to phenotype:

- Isolated hypercholesterolemia: High levels of LDL cholesterol (low-density lipoprotein).

- Isolated hypertriglyceridemia: TG elevation.

- Mixed hyperlipidemia: LDL cholesterol and TG elevation.

- HDL-cholesterol low insulated: Low levels of HDL-cholesterol (high-density lipoprotein).

Classification according to etiopathogenesis:

- Primary dyslipidemia: Genetic in origin and not associated with diseases. It is generally less common than secondary type.

- Secondary dyslipidemia: Produced as a result of some pathology.

To diagnose this disease it is necessary to determine the profile of lipoprotein levels according to ATP III criteria (Table 1) [3].

\begin{tabular}{|l|c|}
\hline \multicolumn{2}{|c|}{ LDL } \\
\hline$<100$ & Optimal \\
\hline $100-129$ & Near or above the optimal \\
\hline $130-159$ & Himit \\
\hline $160-189$ & Very high \\
\hline$\geq 190$ & \\
\hline Total cholesterol & Desirable \\
\hline$<200$ & Limit \\
\hline $200-239$ & High \\
\hline$\geq 240$ & \\
\hline HDL & Low \\
\hline$<40$ & High \\
\hline$\geq 60$ & \\
\hline
\end{tabular}

Table 1: Classification of Adult Panel Treatment III, total cholesterol bound to low density lipoprotein (LDL) and high density (HDL).

There are two treatments for this pathology, one pharmacological and one non-pharmacological, described below:

- Pharmacologically: Statin, a reductase HMG-CoA inhibitor, a key enzyme that regulates the rate of cholesterol biosynthesis, causing a decrease in LDL concentration by between $20-60 \%$, reduces TG by $10-30 \%$ and increases HDL by about $6-12 \%$. In addition to its lipid-lowering effect, other beneficial of statins such as stabilization of atheroma plaques, antioxidant capacity and improved endothelial function have been described, preventing the development of acute cardiovascular events [1].

- Non-pharmacological: This includes diet and physical activity. On the one hand, it recommended to perform physical activity, mainly aerobic exercise such as: fast walks, jogging, swimming, etc. In this sense, physical activity is a key point, there is evidence that regulates and reduces mortality from cardiovascular diseases. This positive effect would be given through different mechanisms that reduce levels of LDL, TG and increase HDL [1]. With regard to diet, it finds indications according to the type of dyslipidemia that occurs: for hypertriglyceridemia treatment focuses on weight reduction, decreased intake of refined and fructose sugars, alcohol, smok- 
ing cessation, consumption of less than $30 \%$ of total calories as lipids, but increasing fiber and monounsaturated fats (up to $15 \%$ ) and reduce total calorie intake in the event of excess malnutrition [1]. While, hypercholesterolemia seeks to progressively reduce intake of saturated fatty acids and cholesterol, promoting consumption of polyunsaturated fatty acids, omega 3 and fiber and limiting excessive refined sugar (sucrose) along with alcohol consumption.

For dietary treatment of dyslipidemia it is recommended to include dietary fiber [1]. According to Codex Alimentarius (2011) it is defined as "carbohydrate polymers, with a degree of polymerization $>3$, which are not hydrolyzed by endogenous enzymes in the small intestine of humans" and belong to one of the following categories [8]:

- Naturally occurring in the food as consumed.

- Obtained from food raw material by physical, enzymatic or chemical means.

- Synthetic

It is classified into two types: insoluble and soluble. The National Cholesterol Education Program Adult Treatment Panel (NCEP ATP III) recommends regular consumption of 20-30 g/day of total fiber to reduce the risk of developing cardiovascular disease by 12 to $20 \%$ [7]. It has been observed that soluble fiber has a greater effect than insoluble [12], so consumption of 10-25 $\mathrm{g}$ of soluble fiber is recommended.

Flaxseeds are composed of both types of fiber, the insoluble fraction is composed mainly of cellulose and lignin and the soluble part mainly by mucilage, which is extracted with heat or cold water [10]. The soluble fraction has hypoglycemic and hypocholesterolemic function, on the other hand, the insoluble increases the volume of faeces by reducing intestinal transit time [11].

The soluble fiber in the small intestine slows the transit time due to the formation of viscous solutions, in addition increases the thickness of the layer of water that must pass through the solutes to reach the membrane of the enterocyte, which results in a decrease in the absorption of glucose, lipids and aminoacids. This is related at the same time to a lower absorption of bile salts, as they are joined to phenolic and uronic residues in the matrix of polysaccharides. This situation affects the micell formation and fat absorp- tion, resulting in a loss of bile salts, decreasing cholesterol levels, as this is beginning to be used for the de novo synthesis of new bile salts. Regular intake of soluble fiber has positive effects on cholesterol control. This could be explained by the benefits of fiber in relation to the ability to limit the absorption of intestinal cholesterol and chelating (I am not sure about this word) action on bile salts. In addition, has been seen that propionate (Short-chain fatty acid product of fiber fermentation), after being absorbed from the colon into the portal circulation, can act by inhibiting HMG-CoA reductase, decreasing endogenous cholesterol synthesis [12].

It is recommended to consume crushed flaxseed because the digestibility and bioavailability of its components are greater compared to whole flaxseed. When people consume the whole seed, it passes directly into the gastrointestinal tract without being digested, because the seed cover is resistant to digestive enzymes. Unlike ground flaxseed that destroys the seed cover leaving inside nutrients exposed to digestive action [9]. In 2014, Health Canada approved a statement about flaxseed and health, indicating that the intake produces a reduction in blood cholesterol [13].

There are several published research that would demonstrate the positive effect of flaxseed. One of which was performed with a daily supplementation of $40 \mathrm{~g}$ of this seed in 199 healthy menopausal women for 12 months. This administration reduced total cholesterol concentrations [14]. Another study was conducted by supplementing rats with ground flaxseed. Finally serum TG, total cholesterol and LDL were significantly lower [15].

\section{Materials and Methods}

\section{Type of study}

Clinical trial, control case. An experimental study was carried out using ground flaxseed in Valparaíso, Chile with the previous approval of the University's Bioethics Commission.

\section{Population description}

The target participants consisted in (I am not sure of this) men and women between 40 and 70 years of age, coming from Valparaiso city. A selection of 10 people was made ( 5 with drug treatment and 5 without drug treatment), of which 7 were women and 3 men. The call was made through social media and posters.

The number of individuals to recruit was defined by the resources available for intervention. 


\begin{tabular}{|l|c|}
\hline \multicolumn{1}{|c|}{ Inclusion criterion } & Exclusion criterion \\
\hline Dyslipidemia diagnosed & $\begin{array}{c}\text { Diagnosis of } \\
\text { genetic dyslipidemia }\end{array}$ \\
\hline $\begin{array}{l}\text { Pharmacological treatment of } \\
\text { statins. }\end{array}$ & Allergies to weeds \\
No drug treatment. & $\begin{array}{r}\text { Pathologies that affect } \\
\text { lipid metabolism such as } \\
\text { diabetes, }\end{array}$ \\
\hline Age 19 to 70 (inclusive) & $\begin{array}{r}\text { insulin resistance or } \\
\text { metabolic syndrome. }\end{array}$ \\
\hline Sedentary &
\end{tabular}

Table 2: Inclusion/exclusion criteria

\section{Intervention and procedure}

The selected subjects were their own control, i.e. individual variations were evaluated. They were requested to attend a meeting at which they were explained the procedure to be followed from day 0 to the 28th of intervention. Each subject who decided to participate, signed an informed consent to be part of the study. It was indicated to consume 15 grams of ground flaxseed in $200 \mathrm{cc}$ of sugar-free reconstituted juice along with their usual lunch. According to data obtained from Food Processor Software, 15 grams of flaxseed provide 4,19 grams of total fiber. The seed was delivered divided into individual bags of 15 grams for each day of the month (28 days), and the subjects were responsible to grind it in a blender with the juice at the time of consumption. These were stored by individuals at room temperature.

\section{Blood tests}

Two lipid-profile blood tests (total cholesterol, LDL, HDL, and blood TG) were performed, the first before starting to consume ground flaxseed, and the second test after one month of starting intake. On both occasions patients fasted for at least 9 hours prior to blood draw (2-5 ml) [17].

\section{Statistical analysis}

The results were analyzed by each individual by comparing percentages between the first and second examinations. Subsequently they were obtained by analyzing one delta per individual (difference between the initial value parameter and after the follow-up month), these were measured with the average of each individual

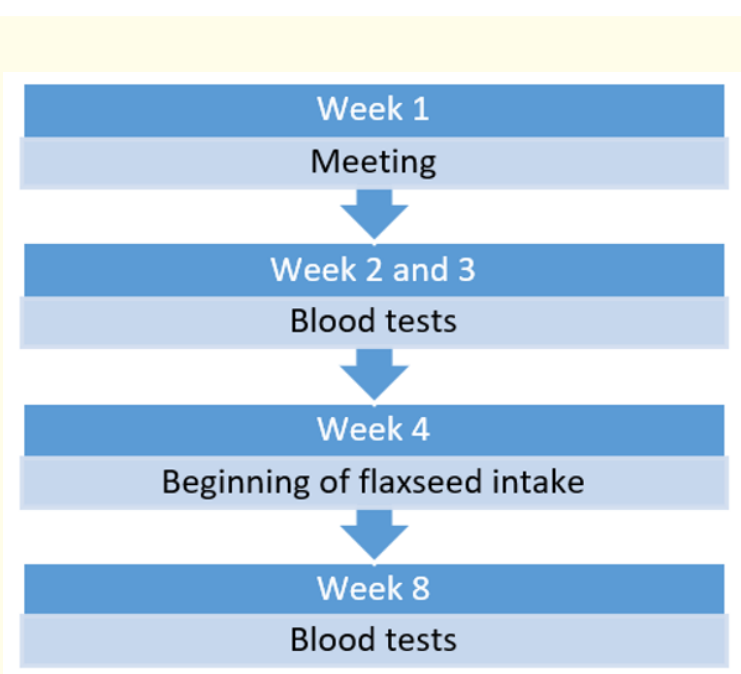

Figure 1: Procedure.

plus standard deviation. This was compared using variance (ANOVA). T-Student was used to compare the average intakes before and after administration. In both tests the differences were considered significant $(\mathrm{p}<0.05)$.

\section{Results and Discussion}

Of the initial 10 participants, 1 did not complete the procedure, and 1 was excluded for an exclusionary disease, so they could not be included in the final results.

The remaining 4 individuals with drug treatment and the remaining 4 without drug treatment received supplementation with 15 grams of soluble fiber through consumption of ground flaxseed. Age and body mass index (BMI) were similar in both groups, both presenting an overweight nutritional status.

\begin{tabular}{|l|c|c|}
\hline & No drug & With drug \\
\hline Age & $53 \pm 2,83$ & $55,8 \pm 8,96$ \\
\hline BMI & $28,54 \pm 3,94$ & $26,6 \pm 2,11$ \\
\hline
\end{tabular}

Table 3: Age and body mass index (BMI) of participants.

The difference of consumption in energy, carbohydrates, proteins, lipids, total fiber and soluble fiber did not very significantly $(\mathrm{p}>0.05)$. All the participants followed the recommendation of not change their level of physical activity during the weeks. 
A decrease of $23 \%$ in LDL were significant in both groups $(\mathrm{p}=$ 0.04). By contrast, variations in total cholesterol, HDL and TG were not significant ( $\mathrm{p}>0.05$ ), so flaxseed could not be associated with these variables.

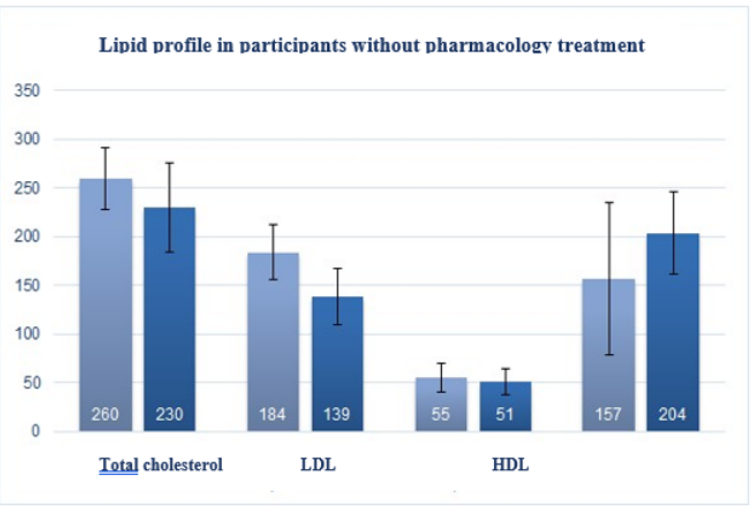

Figure 2: Averages of pre and post supplementation results for total cholesterol, LDL, HDL and triglycerides over standard deviation in subjects without drug treatment.

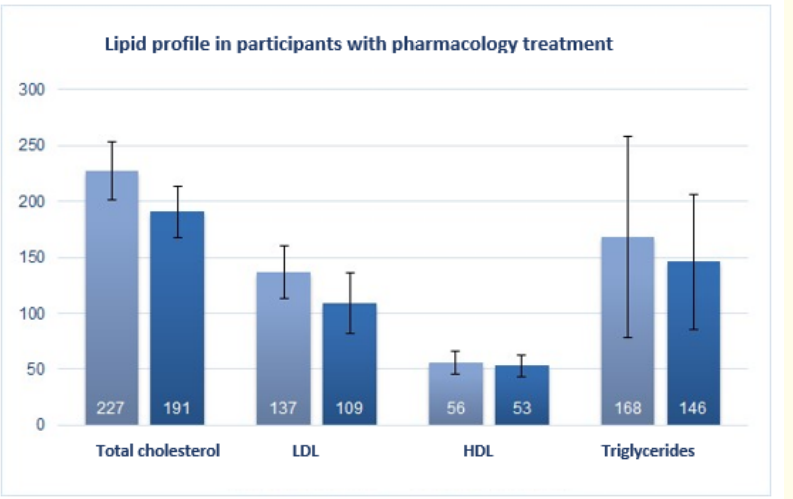

Figure 3: Averages of pre and post supplementation results for total cholesterol, LDL, HDL and triglycerides over standard deviation in subjects with drug treatment.

\section{Discussion}

Dyslipidemia is a disease that is associated with metabolic abnormalities that are related to variations in lipid profile [1]. Soluble fiber is an essential element in nutrition, as it performs important functions such as: regulating transit through the colon, reducing glucose, total cholesterol rates in the blood, delaying its absorption and delaying gastric emptying [21]. In fact, there are evidence in animal and human models that this type of fiber would produce positive variations in plasma lipids, as reported in Ruiz M research, involving 30 patients with dyslipidemia, where they were indicated to consume 60 grams of liquefied oats in water over three months, achieving a statistically significant decrease in total cholesterol and LDL [20].

In view of the results obtained in this study, it can be said that there was a significant decrease in LDL following an intake of 15 grams of ground flaxseed administered in overweight sedentary adults (40 - 70 years) (according to BMI) over a period of one month, with no significant changes in intake of macronutrients, total and soluble fibre ( $p>0.05$ ), regardless of whether or not they were with drug treatment. Result similar to Brown M research that controlled 67 trials and obtained that soluble fiber was associated with decreases in LDL [6].

Another study worked with a sample of 97 patients of both genders for 3 months, diagnosed with dyslipidemia, between the ages of 40 and 70, where the use of fiber (oats) also showed a decrease of $15 \%$ in total cholesterol after treatment [19].

Changes in LDL could be based on increasing the accessibility of dietary fiber by crushing the seed, being able to associate that to the change in the food matrix of flaxseed the soluble fiber was more available for use. It is able to ferment in the colon producing short-chain fatty acids (acetate, propionate and butyrate), which suppress cholesterol synthesis in the gut [22]. In addition, it produces alterations in the homeostasis of bile acids by interrupting their enterohepathic circulation, increasing the production in the liver of bile acids from cholesterol, thus decreasing free cholesterol deposits. To restore these deposits there is a regulation of LDL receptors, which results in a decrease in plasma col-LDL [23].

As for the significant decrease in LDL cholesterol, it may be due to the consumption of phytosterols found in the flaxseed. Numerous scientific evidence from controlled clinical studies concludes that the consumption of phytosterols at doses of 1.5 to $4 \mathrm{~g} /$ day lowers cholesterol by an average of $10 \%$. 
In another study that was conducted for 8 weeks, 3 grams of stanol (reduced form of phytosterols), caused the decrease in col-total and LDL (6\% and $10 \%$ respectively) and in a last study conducted with preparations of soy beans (rich in phytosterols) it reduce total cholesterol and LDL by 5-13\% with non-effect on the HDL [25].

However, it is important to mention that according to food intake reported (before and after flaxseed supplementation), patients did not report significant changes in their diets.

To corroborate the findings of this research it is necessary to carry out other longer longitudinal studies and with bigger group to verify the results, in order to be able to extrapolate them to another context.

\section{Conclusion}

Due to the epidemiological profile of the population, in which a high prevalence of cardiovascular diseases has developed, food plays an important role in the treatment of cardiovascular diseases.

Soluble fiber has demonstrated many benefits in people's health, some of them are associated with a hypolipidemic function. One source of this is flaxseed, so its consumption turns out to be beneficial in people with dyslipidemia, improving their lipid profile.

A supplementation with 15 grams of ground flaxseed consumed in the lunch for 1 month, produce a decrease in LDL cholesterol in dyslipidemic sedentary adults, with or without drug treatment, despite being a short-term study.

However, to establish recommendation it is necessary to carry out longer longitudinal studies with a bigger group of participants.

\section{Conflict of Interest}

We don't have any conflict of interest exists.

\section{Bibliography}

1. Ministerio de Salud, Chile. "Normas Técnicas Dislipidemias". (2017).

2. Miguel S., et al. "Dislipidemias”. ACIMED 20.6 (2009): 265-273.

3. U.S. Departament of Health and Human Services. "ATP III Guidelines At-A-Glance Quick Desk Reference" (2017).
4. C Carvajal. "Lipoproteins: metabolism and atherogenic lipoproteins., of Costa Rican Legal Medicine" (2017).

5. Ministerio de Salud, Chile. “Dislipidemias” (2000).

6. Octavio M., et al. "Cholesterol : Biological function and medical implications". Revista Mexicana De Ciencias Farmacéuticas 43.2 (2012).

7. Angeles C. "Manual de Nutrición y Dietética, Fibra Dietética". Universidad Complutense de Madrid. (2017).

8. Juliet G. “Dietary fiber”. ILSI (2017).

9. Fernando F., et al. "Lyxse as a source of bioactive compounds for food processing". Agro sur 36.2 (2008).

10. Shim Y., et al. "Flaxseed (Linum usitatissimum L.) bioactive compounds and peptide nomenclature: A review". Journal Trends in Food Science and Technology 38.1 (2014).

11. Kátia C., et al. "Efecto de la semilla de linaza en el crecimiento de ratas wistar". Revista Chilena de Nutricion 35.4 (2008).

12. Squire A. et al. "Dietary fiber". Hospital Nutrition 21 (2006): 61-72.

13. Linda M. "Flaxseed- ancient grain rich in health and cooking benefits". Healthy Flax (2015).

14. S Dodin. "The Effects of Flaxseed Dietary Supplement on Lipid Profile, Bone Mineral Density, and Symptoms in Menopausal Women: A Randomized, Double-Blind, Wheat Germ PlaceboControlled Clinical Trial". Journal of Clinical Endocrinology and Metabolism 90.3 (2005): 1390-1397.

15. W Ratnayake. " Chemical and nutritional studies of flaxseed (variety Linott) in rats de The Journal of Nutritional Biochemistry". Journal of Nutritional Biochemistry 3.5 (1992).

16. A Catalina. "Efecto del consumo de linaza en el perfil lipídico, el control del cáncer y como terapia de reemplazo hormonal en la menopausia: una revisión sistemática de ensayos clínicos aleatorizados". Perspectivas en Nutrición Humana 13.1 (2011): 73-91.

17. Marambio I. "Exámenes de laboratorio ¿Qué es el perfil lipídico?" Clínica Alemana (2017). 
18. Lisa B. "Cholesterol-lowering effects of dietary fiber: a meta-analysis". The American Journal of Clinical Nutrition 69.1 (1999): 30-42.

19. Aura M., et al. "Efecto de la avena y/o lovastatina sobre el perfil lipídico en pacientes dislipidémicos del hospital de Tunjuelito, Bogotá". Revista U.D.C.A Actualidad and Divulgación Científica 16.2 (2013): 319-326.

20. Ruiz F. "Consumo de avena (Avena sativa) y prevención primaria de la dislipidemia en adultos sin restricción dietética". Atención Familiar 18.2 (2011).

21. Sastre G. "Fibra y prebióticos: conceptos y perspectivas". Revista Gastroenterología y Hepatología 26 (2003): 6-12.

22. Fernández C., et al. "La fibra dietética en la prevención del riesgo cardiovascular". Revista Nutrición Clínica y Dietética Hospitalaria 30.2 (2010): 4-12.

23. Octavio M., et al. "Colesterol: Función biológica e implicaciones médicas, de Revista mexicana de ciencias farmacéuticas". Revista Mexicana De Ciencias Farmacéuticas 43.2 (2012).

24. Valenzuela A., et al. " Fitoesteroles y fitoestanoles: aliados naturales para la protección de la salud cardiovascular". Revista Chilena de Nutrición 31 (2004): 161-169.

25. Muñoz A., et al. "Fitoesteroles y fitoestanoles: Propiedades saludable". Revista Horizonte Médico 11.2 (2011).

\section{Volume 5 Issue 7 July 2021}

\section{(C) All rights are reserved by $M$ Paz Beyer., et al.}

